See Article page 132.

\section{Commentary: Left ventricular assist device exchange: Have we found the golden ticket?}

Arman Kilic, MD

In this issue of the Journal, Barac and colleagues ${ }^{1}$ report the Duke experience with left ventricular assist device (LVAD) exchange to the HeartMate 3 device (Abbott Laboratories, Abbott Park, Ill). This is an important contribution to the literature, representing a large series of LVAD exchanges despite what may seemingly be viewed as low patient numbers. Indeed, the fact that there were only 19 exchanges to the HeartMate 3, with 16 to the HeartWare LVAD (HeartWare International Inc, Framingham, Mass) and 69 to the HeartMate II device (Abbott), limits the ability to perform any meaningful risk adjustment. At closer look, the number of patients at risk in the HeartMate 3 group at 1 year is only 6 patients. These results must therefore be interpreted with statistical caution, but the survival and reoperation figures seem to speak for themselves-there does appear to be a difference.

The Multicenter Study of MagLev Technology in Patients Undergoing Mechanical Circulatory Support Therapy with HeartMate 3 (MOMENTUM 3) trial compared outcomes of LVAD implantation with the HeartMate 3 versus the HeartMate II, enrolling both patients with bridge-totransplant and destination LVAD support. ${ }^{2}$ Importantly, LVAD exchanges were excluded. At 2 years, more patients receiving the HeartMate 3 were alive and free of disabling stroke or reoperation for device malfunction $(76.9 \%$ vs $64.8 \% ; P<.001)$. The pump replacement rate at 2 years was only $2.3 \%$ with the HeartMate 3 . These encouraging results confirm that we have made strides in the field of LVAD therapy, and the current report by Barac and colleagues $^{1}$ confirms that, even in the setting of LVAD exchange, this pump has laudable performance.

\footnotetext{
From the Division of Cardiac Surgery and Heart Transplant, Department of Cardiovascular Surgery, University of Pittsburgh Medical Center, Pittsburgh, Pa. Disclosures: Author serves on a medical advisory board for Medtronic, Inc. Received for publication Oct 24, 2019; revisions received Oct 24, 2019; accepted for publication Oct 24, 2019; available ahead of print Nov 13, 2019.

Address for reprints: Arman Kilic, MD, University of Pittsburgh Medical Center, 200

Lothrop St, Suite C-700, Pittsburgh, PA 15213 (E-mail: kilica2@upmc.edu).

J Thorac Cardiovasc Surg 2020;160:143-4

$0022-5223 / \$ 36.00$

Copyright (C) 2019 by The American Association for Thoracic Surgery

https://doi.org/10.1016/j.jtcvs.2019.10.139
}

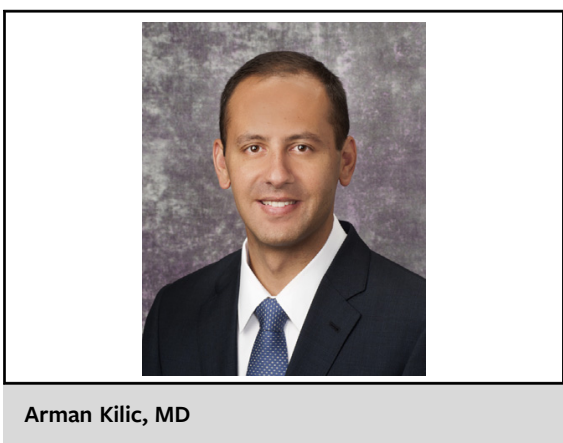

CENTRAL MESSAGE

Barac and colleagues report

improved outcomes with ex-

change of left ventricular assist

devices to the HeartMate 3 de-

vice. But is it advantageous to

avoid a redo sternotomy in some

scenarios?

An important technical detail that cannot be overlooked, however, is that exchanges to the HeartMate 3 in this series were all performed with redo sternotomy, whereas exchanges to the HeartWare or HeartMate II devices were sternal sparing. An advantage of a HeartMate II to HeartMate II exchange is that it can be done with a subcostal incision, and even without the use of cardiopulmonary bypass. This can certainly be advantageous when dealing with a hostile chest, an older patient, or a patient with a significant comorbidity burden. A quick glance at the baseline characteristics in the study of Barac and colleagues ${ }^{1}$ reveals an average age of 56.8 years, with $5 \%$ receiving mechanical ventilatory support, $14 \%$ on intravenous inotropic therapy, and median creatinine and bilirubin levels of 1.2 and 1.4 , respectively. What should we do with a 75-year-old with a HeartMate II who requires LVAD exchange? What about a 65-year-old with a HeartMate II who is intubated, has significant right ventricular dysfunction, and has compromised end-organ function? Often LVAD exchanges requiring redo sternotomy can be bloody, with tedious mediastinal adhesiolysis, which can lead to large quantities of blood product transfusion and ensuing right-sided heart failure. The rates of severe postoperative right ventricular dysfunction in this series were $31.6 \%$ in the HeartMate 3 group and only $17.6 \%$ in the control cohort, which may suggest a difference that would reach significance with larger patient numbers. Postoperative transfusion requirements are not 
provided, but they may be different between the groups. Barac and colleagues ${ }^{1}$ are to be congratulated on their excellent outcomes in a difficult patient population. Nonetheless, we should leave in our armamentarium the option for less invasive exchange operations, particularly for patients on the high end of the operative risk spectrum.

\section{References}

1. Barac YD, Wojnarski CM, Junpaparp P, Jawitz OK, Billard H, Daneshmand MA, et al. Early outcomes with durable left ventricular assist device replacement using the HeartMate 3. J Thorac Cardiovasc Surg. 2020;160:132-9.e1.

2. Mehra MR, Uriel N, Naka Y, Cleveland JC Jr, Yuzefpolskaya M, Salerno CT, et al; MOMENTUM 3 Investigators. A fully magnetically levitated left ventricular assist device—final report. $N$ Engl J Med. 2019;380:1618-27. 